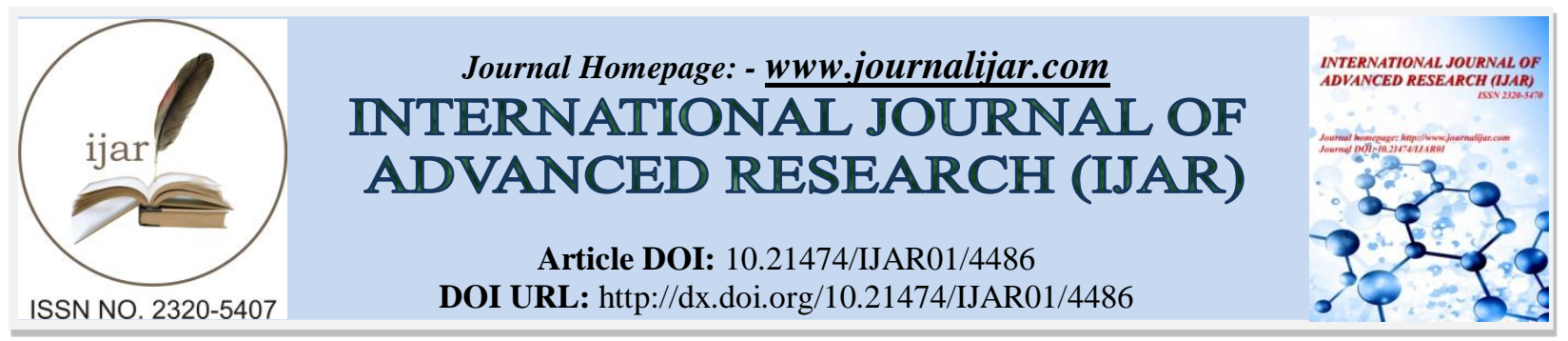

RESEARCH ARTICLE

\title{
ISOLATION AND CHARACTERIZATION OF CARBENDAZIM-DEGRADING BACTERIA IN RICE PADDY SOIL IN CAN THO, VIETNAM.
}

\author{
Hong Phuong Le, Thanh Khang Le and *Thi Phi Oanh Nguyen. \\ Department of Biology, College of Natural Sciences, Can Tho University, 3/2 street, Xuan Khanh ward, Ninh Kieu \\ district, Can Tho city, Vietnam.
}

\section{Manuscript Info}

.....................

Manuscript History

Received: 14 April 2017

Final Accepted: 16 May 2017

Published: June 2017

Key words:-

carbendazim, chemotaxis,

biodegradation

\section{Abstract}

Carbendazim is one of the most commonly used fungicides in Vietnam in recent decades. The intensive application of this pesticide has led to the increase of its presence in soil, surface water, and ground water. This study reports the isolation and characterization of carbendazim-degrading bacterial isolates obtained from pesticidetreated rice paddy soil in Can Tho, Vietnam. Three bacterial isolates capable of utilizing carbendazim as sole carbon source and performing chemotaxis towards carbendazim were isolated. All of them were able to degrade $90 \%$ of carbendazim at concentration of $200 \mathrm{mg} \mathrm{L}^{-1}$ after 6 days of incubation. These isolates were identified as Pseudomonas sp. CT-VT7, Acinetobacter sp. CT-VT9, and Stenotrophomonas sp. CTVT13 based on their 16S-rRNA gene sequences. The results indicate that these strains are potential candidates for carbendazim biodegradation and could be used for applied study on carbendazim removal in the environment.

Copy Right, IJAR, 2017,. All rights reserved.

\section{Introduction:-}

Carbendazim (methyl N-(1H-benzimidazol-2-yl)carbamate) is one of the main systemic benzimidazole fungicides which has been extensively used to control a wide range of fungal diseases on fruits, vegetables, cereals, and ornamental plants (Cancela, Taboada, and Sáchez-Rasero, 1992). This compound is also the primary degradation product of other fungicides, benomyl and thiophanate-methyl (Helweg, 1977). In soil, carbendazim might remain in an immobilized state for a long period due to its slow degradation rate, low solubility in water, and its interaction with soil colloids. The adsorption of this fungicide by soils depends on the organic carbon and clay contents (Cancella et al., 1992; Berglof et al., 2002). Previous studies reported that the half-life of carbendazim was 6-12 months on bare soil and 3-6 months on turf (Baude, Pease, and Holt, 1974). Furthermore, carbendazim is also taken up easily by plants and accumulated in plant tissues. An investigation on Rough lemon seedlings showed that carbendazim concentration in leaves reached the amount of $40 \mu \mathrm{g} \mathrm{g}-1$ leaf tissue at 73 days after treatment. The degradation rate of this toxicant in leaves was slow, i.e. $10 \%$ in 35 days (Solel, Sandler, and Dinoor, 1979). As a result, accumulation of carbendazim in soil and in plants may result in the spread of its residue along the food chain. Many studies reported that carbendazim exposure caused many severe effects on animals including reproductive toxicity in rats (Nakai et al., 1992, 2002; Rajeswary et al., 2007; Yu et al, 2009), down-regulation of humoral immunity in chickens (Singhal et al., 2003), and induction of abnormalities in the development of human ovarian granulose-like tumor cell line (Morinaga et al., 2004).

Corresponding Author:- Thi Phi Oanh Nguyen. 
Although carbendazim might be decomposed by both chemical and physical processes, microbial degradation plays a crucial role in carbendazim removal in soil (Helweg, 1977; Fleeker et al., 1974; Yarden et al., 1990; Mazellier et al., 2003). Until now, many bacterial strains have been reported to degrade completely or partially carbendazim consisting of Ralstonia sp. (Zhang et al., 2005), Pseudomonas sp. CBW (Fang et al., 2010), Rhodococcus jianlingiae djl-6-2 (Wang et al., 2010), Rhodococcus erythropolis djl-11 (Zhang et al., 2013), Bacillus subtilis (Salunkhe et al., 2014), Streptomyces albogriseolus, and Brevibacillus borstelensis (Arya and Sharma, 2015), Stenotrophomonas sp., Klebsiella oxytoca, and Flavobacterium johnsoniae (Alvarado-Gutiérrez et al., 2017).

In Vietnam, especially in the Mekong delta, agriculture is one of the primary components of the economy. To achieve the high crop yield, the use of various pesticides including carbendazim at higher doses has been observed in recent decades, resulting in the contamination of surface water, soil, and sediments. In addition, the absence of a strong legal framework to control the usage of pesticides and the ignorance of farmers about the risk of pesticides have resulted in negative effects on public health and the environment (Minh et al., 2008; Lamers et al., 2011; Thuy et al., 2012). Nevertheless, research on pesticide degradation, especially biodegradation of carbendazim in the Mekong delta is still humble in number. Some research explained the sorption of carbendazim on soils (Berglof et al., 2002) and monitored carbamate, pyrethroides, and triazoles residues in sediment and surface water (Toan et al., 2013). Therefore, this study aimed at isolation of bacteria able to degrade carbendazim from rice paddy soil with a long history of carbendazim application. The efficiency of carbendazim degradation and the chemotactic response towards carbendazim of the isolates were also investigated.

\section{Materials and Methods:-}

\section{Chemicals:-}

Carbendazim (97\%) (Sigma-Aldrich, USA) was used in this study. Other chemicals used in minimal medium (MM), Tryptone Soya Agar (TSA), Tryptone Soya Broth (TSB), toluene, and acetone were purchased from Merck, USA.

\section{Collection of soil samples:-}

Soil samples were collected from two long-term pesticide-treated rice fields in Vinh Thanh district, Can Tho city. At each field, five top soil samples (500 g per sample) till a depth of approximately $10 \mathrm{~cm}$ taken in the middle and at four corners of the field were thoroughly mixed to finally obtain one sample for each field. These samples were stored at $40 \mathrm{C}$ prior to use (Nguyen, 2014).

\section{Enrichment and isolation of carbendazim-degrading isolates;-}

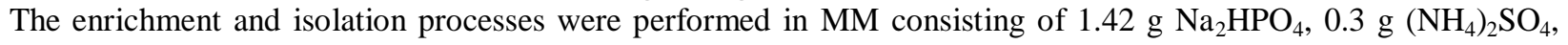
$98.5 \mathrm{mg} \mathrm{MgSO} \mathrm{M}_{4} .7 \mathrm{H}_{2} \mathrm{O}, 5.75 \mathrm{mg} \mathrm{CaCl} 2.2 \mathrm{H}_{2} \mathrm{O}, 3.2 \mathrm{mg} \mathrm{Na}$-EDTA, $2.75 \mathrm{mg} \mathrm{FeSO}{ }_{4} .7 \mathrm{H}_{2} \mathrm{O}, 1.7 \mathrm{mg} \mathrm{MnSO}{ }_{4} \cdot \mathrm{H}_{2} \mathrm{O}, 1.16$ $\mathrm{mg} \mathrm{H}_{3} \mathrm{BO}_{3}, 1.15 \mathrm{mg} \mathrm{ZnSO}{ }_{4} .7 \mathrm{H}_{2} \mathrm{O}, 0.24 \mathrm{mg} \mathrm{CuSO}_{4}, 0.24 \mathrm{mg} \mathrm{CoCl}_{2} .6 \mathrm{H}_{2} \mathrm{O}, 0.1 \mathrm{mg} \mathrm{MoO}_{3}$, and $1 \mathrm{~L}$ distilled water. Five grams of each soil sample was added to Erlenmeyer flasks containing $25 \mathrm{~mL}$ MM supplemented with $200 \mathrm{mg}$ $\mathrm{L}^{-1}$ carbendazim and these flasks were then incubated on a rotary shaker at $125 \mathrm{rpm}$. After 7 days of incubation, 5 $\mathrm{mL}$ of cultures was transferred to another flask with the same conditions. This step was repeated several times until the soil-free cultures were obtained. The cultures were then diluted (10-1 to 10-4) and spread on agar plates containing MM with $200 \mathrm{mg} \mathrm{L}-1$ carbendazim addition. Well-developed and separated colonies were transferred to TSA plates for purification. After several purification steps, pure isolates containing colonies showing identical morphology, size, and color were obtained. The ability of degrading carbendazim of these isolates was confirmed by visualizing their biomass growth when growing them in tubes containing $4 \mathrm{ml} \mathrm{MM}$ with and without $200 \mathrm{mg} \mathrm{L}^{-1}$ carbendazim for 6 days at room temperature on a rotary shaker at $200 \mathrm{rpm}$ (Breugelmans and Uyttebroek, 2004).

\section{Characterization of carbendazim-degrading isolates:-}

Each carbendazim-degrading isolate was grown overnight in $2 \mathrm{~mL}$ TSB medium at room temperature. All cultures were diluted to a density of $\mathrm{OD}_{600 \mathrm{~nm}}=0.5$. Then, $10 \mu \mathrm{L}$ of each preculture was inoculated in test tubes containing 4 $\mathrm{mL}$ MM supplemented with carbendazim (200 mg L-1) as sole carbon source. Each independent isolate was tested with triplicate samples. Abiotic control without bacterial inoculum was also included. These test tubes were shaken at $200 \mathrm{rpm}$ at room temperature for 6 days. During incubation, $4 \mathrm{~mL}$ of each culture were collected at various time intervals, mixed with $4 \mathrm{~mL}$ of toluene:acetone (2:1) solution, and then centrifuged at $5000 \mathrm{x} \mathrm{g}$ for $3 \mathrm{~min}$. The supernatants were taken, added in other test tubes containing $3 \mathrm{~mL}$ toluene:acetone (2:1), and centrifuged at $5000 \mathrm{x}$ $\mathrm{g}$ for $3 \mathrm{~min}$. This step was repeated with test tubes containing $2 \mathrm{~mL}$ toluene:acetone (2:1) and the final supernatants were collected and used to determine the concentration of residual carbendazim concentration by using a high performance liquid chromatography (HPLC) apparatus equipped with a Nucleodur C18 column. The mobile phase 
consisted of acetonitrile and phosphoric acid 0.1\% (50:50) and was applied at a flow rate of $1 \mathrm{~mL} \mathrm{~min}^{-1}$. The peak of carbendazim was detected at $279 \mathrm{~nm}$ by an UV-VIS detector.

\section{Chemotaxis assay of carbendazim-degrading isolates:-}

The chemotaxis assay was performed on Petri dishes containing semi-solid MM (0.75\% agar). Whatman filter paper circles with approximately $2 \mathrm{~cm}$ in diameter were prepared, sterilized and then put on semi-solid agar plates. Carbendazim crystals were then sprinkled around the whole edge or half of the circumference of the filter paper circles. After removal of paper circles by using sterilized tweezers, each carbendazim-degrading isolate was inoculated at the center of the circle of each Petri dish. Bacteria were also inoculated in Petri dishes composed of MM with carbendazim dissolved thoroughly in agar and without carbendazim as positive and negative control treatments, respectively. Each treatment was done in triplicate. All plates were incubated at $32 \mathrm{oC}$, the movement of bacterial isolates towards carbendazim and their biomass growth were observed after 14 days of incubation.

\section{Identification of carbendazim-degrading isolates:-}

Genomic DNA of isolates showing high degradation rates was extracted and amplified using 27f (5'AGAGTTTGATCTGGCTCAG-3') and 1492r (5'-CGGTTACCTTGTTACGACTT-3') primers (Wilmotte, Van der Auwera, and De Wachter, 1993) targetting 16S-rRNA gene. The amplified 16S-rRNA genes were sequenced and analyzed by Geneious R10 software. Carbendazim-degrading isolates were genetically identified by homology searches using BlastN program implemented at NCBI with the 16S-rRNA sequences as queries.

\section{Results:-}

\section{Isolation of carbendazim-degrading isolates:-}

After repeated enrichment and purification processes, fifteen isolates having the ability of growing on MM supplemented with $200 \mathrm{mg} \mathrm{L}^{-1}$ carbendazim as sole carbon source were isolated. Among these, three isolates CTVT7, CT-VT9, and CT-VT13 performing higher biomass growth in comparison to the others were selected for further identification. All three isolates were purified from soil samples collected from one rice field. Isolate CTVT7 formed oyster white, smooth, and convex colonies (Figure 1a). The morphology of CT-VT9 colonies was opaque white, convex, smooth, and entire margins (Figure 1b). The colonies of CT-VT13 were cream, smooth, convex, and entire margins (Figure 1c). The cells of these isolates were rod shaped and they were Gram-negative bacteria (Figure 2).
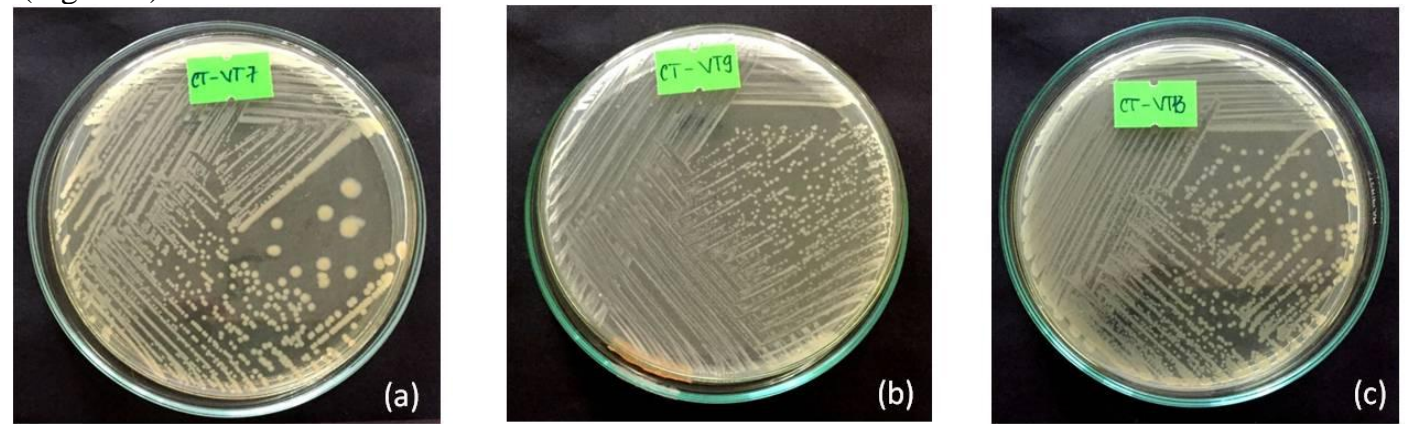

Figure 1:- The colony morphology of three isolates (a) CT-VT7, (b) CT-VT9, (c) CT-VT13.
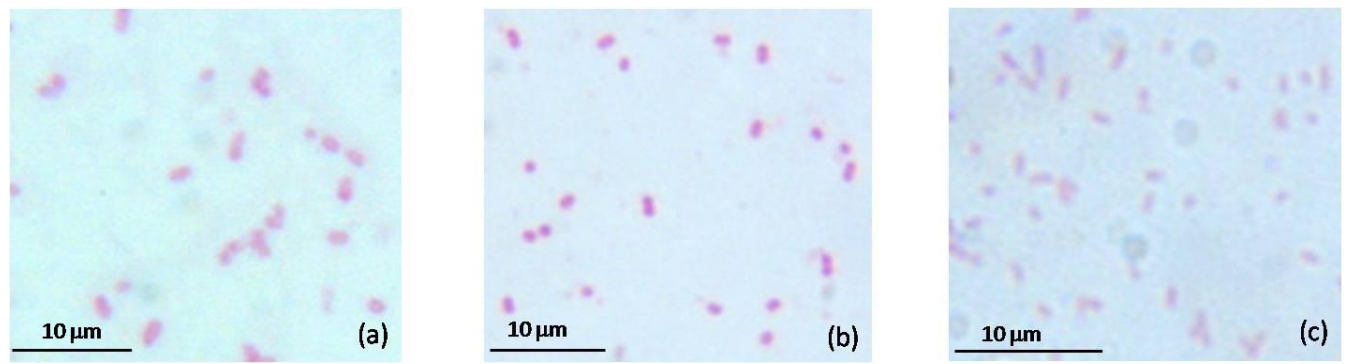

Figure 2:- Light micrograph (1,000x) of the three Gram-stained isolates (a) CT-VT7, (b) CT-VT9, and (c) CTVT13 


\section{Characterization of the carbendazim-degrading isolates:-}

The biomass growth of isolates CT-VT7, CT-VT9, and CT-VT13 was investigated in MM supplemented with carbendazim at three different concentrations, i.e. $50 \mathrm{mg} \mathrm{L}^{-1}, 100 \mathrm{mg} \mathrm{L}^{-1}$, and $200 \mathrm{mg} \mathrm{L}^{-1}$. Our observation revealed that all isolates grew well in MM amended with $200 \mathrm{mg} \mathrm{L}^{-1}$ carbendazim. Hence, this concentration was used for determination of carbendazim degrading efficiency in those isolates.

All investigated isolates were capable of utilizing carbendazim as sole carbon source and they showed similar growth curve and degradation pattern. The optical density of the cultures increased whereas the amount of carbendazim remaining decreased gradually after 6 days of incubation. The data indicated that carbendazim degradation was initiated almost immediately and about $35-40 \%$ of the compound $\left(200 \mathrm{mg} \mathrm{L}^{-1}\right)$ was degraded after 1 day of incubation in three isolates. After 2 days, the efficiency of carbendazim degradation was approximately $70 \%$, followed by $82 \%-84 \%$ at the fourth day. After 6 days of incubation, approximately $90 \%$ carbendazim was metabolized (Figure 3).
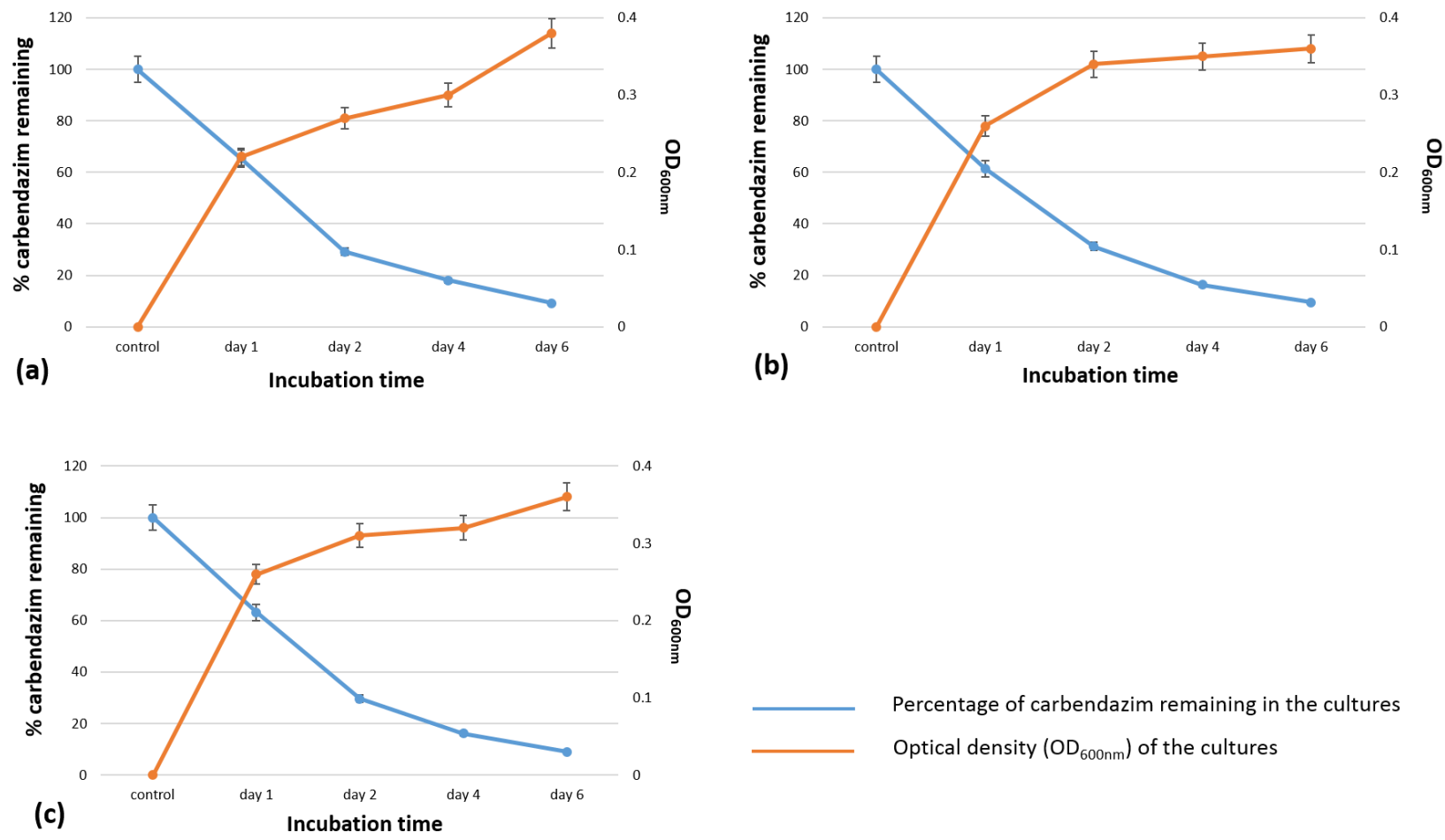

Figure 3:- Degradation of carbendazim and optical density of three isolates in the MM supplemented with carbendazim (200 $\mathrm{mg} \mathrm{L}^{-1}$ ) after 6 days of incubation (a) CT-VT7, (b) CT-VT9, and (c) CT-VT13

\section{Chemotaxis assay of carbendazim-degrading isolates:-}

All three isolates capable of degrading carbendazim effectively were examined for their ability to respond chemotactically to carbendazim. In negative control treatments without carbendazim addition, no biomass growth was observed (Figure 3a) whereas in positive control plates in which carbendazim was dissolved in agar medium, all three isolates formed a clear biomass growth at the inoculation point (Figure 3b). However, when carbendazim crystals were added on agar plates, all isolates grew towards carbendazim crystals by forming biomass as semicircles or whole circles according to the presence of carbendazim (Figure $3 \mathrm{c}$ and $3 \mathrm{~d}$ ) indicating that these isolates are capable of performing chemotaxis towards the compound. 
(a)
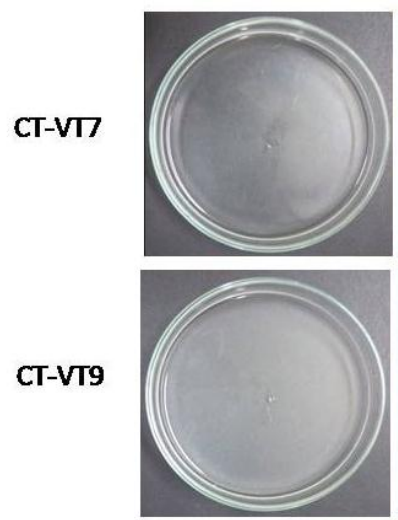

CT-VT13

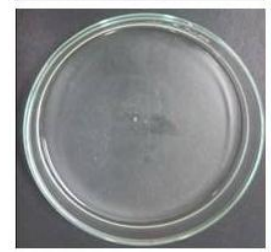

(b)
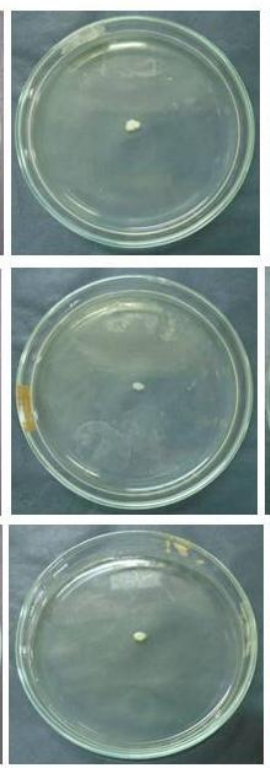

(c)
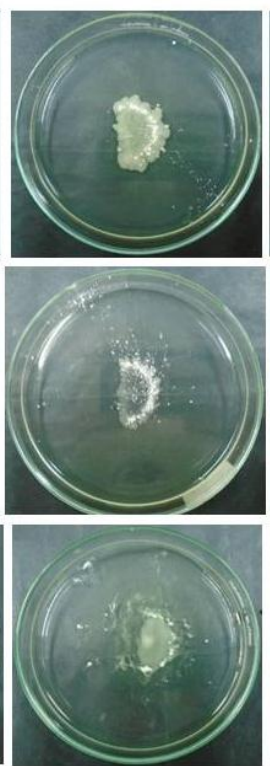

(d)
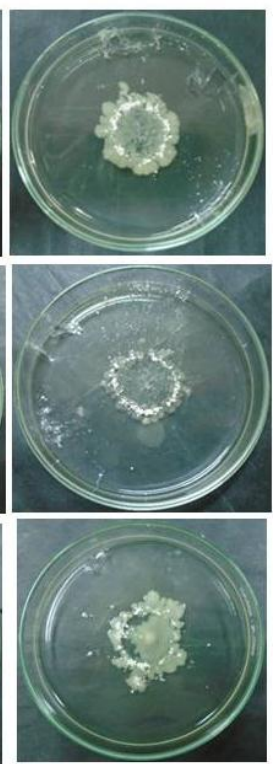

Figure 3:- Chemotaxis responses towards carbendazim crystals of three bacterial isolates on semi-solid agar plates after 14 days of incubation. (a) negative control treatments, (b) positive control treatments, (c) carbendazim crystals were sprinkled in a semicircle shape, (d) carbendazim crystals was sprinkled in a circle shape.

\section{Identification of carbendazim-degrading isolates:-}

Sequence analysis of the 16S-rRNA genes showed that all three isolates CT-VT7, CT-VT9, and CT-VT13 were belonging to the $\gamma$-proteobacteria, representing the genera Pseudomonas, Acinetobacter, and Stenotrophomonas, respectively. To reflect their origin, these strains were designated Pseudomonas sp. CT-VT7, Acinetobacter sp. CTVT9, and Stenotrophomonas sp. CT-VT13 (Table 1).

Table 1:- Preliminary identification of carbendazim-degrading strains isolated from rice paddy soil in Vinh Thanh district, Can Tho city based on 16S-rRNA gene sequences

\begin{tabular}{|c|c|c|c|c|c|c|}
\hline \multirow[t]{2}{*}{ Isolate } & \multirow[t]{2}{*}{ Identification } & \multicolumn{4}{|c|}{ Homology } & \multirow[b]{2}{*}{$\begin{array}{c}\text { E- } \\
\text { value }\end{array}$} \\
\hline & & Organism & Origin & $\begin{array}{c}\text { Identity } \\
(\%)\end{array}$ & $\begin{array}{l}\text { Accession } \\
\text { no. }\end{array}$ & \\
\hline CT-VT7 & $\begin{array}{l}\text { Pseudomonas sp. } \\
\text { CT-VT7 }\end{array}$ & $\begin{array}{l}\text { Pseudomonas taiwanensis } \\
\text { strain } \mathrm{J}\end{array}$ & $\begin{array}{l}\text { paddy soil, } \\
\text { China }\end{array}$ & 99 & KY927411.1 & 0.0 \\
\hline CT-VT9 & $\begin{array}{l}\text { Acinetobacter sp. } \\
\text { CT-VT9 }\end{array}$ & $\begin{array}{l}\text { Acinetobacter schindleri } \\
\text { strain KSR11 }\end{array}$ & water, India & 99 & KY458542.1 & 0.0 \\
\hline CT-VT13 & $\begin{array}{l}\text { Stenotrophomonas } \\
\text { sp. CT-VT13 }\end{array}$ & $\begin{array}{l}\text { Stenotrophomonas sp. } \\
\text { ABO40 }\end{array}$ & $\begin{array}{c}\text { rhizospheric } \\
\text { soil, India }\end{array}$ & 99 & KR082280.1 & 0.0 \\
\hline
\end{tabular}

\section{Discussion:-}

This is the first study on isolation of carbendazim-degrading bacteria in the Mekong delta of Vietnam in which three bacterial isolates having ability to degrade carbendazim effectively were isolated from long-term pesticide-treated rice paddy soil in Vinh Thanh district, Can Tho city, Vietnam. All three isolates showed effective carbendazim degradation capability with $90 \%$ of carbendazim was degraded after 6 days of incubation. It is interesting to note that these isolates also performed chemotactic response towards the fungicide carbendazim. It was proven that the persistence of pollutants in the ecosystems was primarily due to their limited water solubility and sorption to solid particles that protects them from microbial attack (Habe and Omori, 2003). In soil environment, pollutants are often non-homogeneously distributed, therefore, performing a chemotactic response towards such pollutants might be an important advantage for organic xenobiotic-degrading bacteria, enabling detection and migration to pollutant sources in soil (Grimm and Harwood, 1997). Different organic xenobiotic-degrading bacteria have indeed been shown to perform chemotaxis towards organic pollutants, including monocyclic and polycyclic aromatic hydrocarbons, alkanes, nitroaromatics and chlorinated pesticides. For instance, Pseudomonas putida has been proven to have the ability to 
detect and swim towards some pollutants including benzene, toluene, and trichloroethylene (Parales, Ditty, and Hardwood, 2000). Another study also showed that naphthalene, a toxic organic compound, was also a chemoattractant of Pseudomonas spp. (Grimm and Hardwood, 1997). In soils, carbendazim is degraded slowly, mainly through microbial degradation (Helweg, 1977). However, due to its low water solubility, the fungicide distributes very limited from the application point to the vicinity both horizontally and vertically, resulting in its persistence in the ecosystems (Solel et al., 1979). Therefore, the ability of carbendazim-degrading bacteria investigated in this study to navigate towards carbendazim might enable them to detect, locate, and degrade effectively residual carbendazim in soils. Up to now, to the best of our knowledge, no information on chemotaxis characteristics of carbendazim-degrading bacteria was reported. Hence, further research would be needed to investigate the genetics behind chemotactic response of these carbendazim-degrading bacteria.

The three potential candidates for carbendazim degradation obtained from this study were Gram negative bacteria and genetically identified as Pseudomonas sp. CT-VT7, Acinetobacter sp. CT-VT9, and Stenotrophomonas sp. CTVT13 based on their 16S-rRNA sequences. In previous studies conducted in China, India, and Mexico, carbendazim was degraded by both Gram-positive and Gram-negative bacterial strains including Ralstonia sp. (Zhang et al., 2005), Pseudomonas sp. CBW (Fang et al., 2010), Rhodococcus jianlingiae djl-6-2 (Wang et al., 2010), Rhodococcus erythropolis djl-11 (Zhang et al., 2013), Bacillus subtilis (Salunkhe et al., 2014), Streptomyces albogriseolus, and Brevibacillus borstelensis (Arya and Sharma, 2015), Stenotrophomonas sp., Klebsiella oxytoca, and Flavobacterium johnsoniae (Alvarado-Gutiérrez et al., 2017). Interestingly, although Acinetobacter has been proven to be capable of degrading various pesticides consisting of atrazine (Singh, Suri, and Cameotra, 2004), methyl parathion (Liu et al., 2007), malathion (Xie et al., 2009), and chlorpyrifos (Pailan et al., 2016), this bacterial genus has not yet been reported for carbendazim degradation. Another study showed that Pseudomonas sp. CBW could degrade carbendazim at concentrations of 1 and $10 \mathrm{mg} \mathrm{L}-1$ at the rate of 87.1 and $99.1 \%$ after 72 -hour incubation, respectively. However, this bacterial strain could not remove carbendazim effectively from the mineral salts medium supplemented with higher concentration of carbendazim $\left(100 \mathrm{mg} \mathrm{L}^{-1}\right)$, i.e. only $9.9 \%$ carbendazim was degraded after 3-day incubation (Fang et al., 2010). In contrast, Pseudomonas sp. CT-VT7 isolated from Vietnamese soil in our study was capable of degrading carbendazim effectively at relatively high concentration (200 $\mathrm{mg} \mathrm{L}^{-1}$ ), i.e. $90 \%$ carbendazim was removed from the inoculated medium after 6 days. Recent study indicated that Stenotrophomonas maltophilia, along with other bacterial strains including Flavobacterium, Klebsiella, and Flectobacillus were isolated from soil and water samples from hydroponic lettuce crops in Mexico, and were utilized for carbendazim degradation in a horizontal tubular biofilm reactor. This microbial communities was capable of removal $95 \%$ carbendazim from the minimal mineral salts medium supplemented with $30 \mathrm{mg} \mathrm{L}^{-1}$ commercial carbendazim (50\% active ingredient) after an incubation period of $31 \mathrm{~h}$ (Alvarado-Gutiérrez et al., 2017). In addition, a Chinese patent published in 2013 also claimed that Stenotrophomonas sp. DJL1614 could remove $73.4 \%$ carbendazim in $\mathrm{MM}$ supplemented with $500 \mathrm{mg} \mathrm{L}^{-1}$ carbendazim after 10 days of incubation (Chinese Patent No. CN1022906041 B). Hence, these previous and our present study suggest that Stenotrophomonas might be able to degrade carbendazim well at both low and high concentrations. In many research on isolation of carbendazim degrading bacteria conducted in China, Rhodococcus was found to have high ability to degrade carbendazim from low to high concentrations at significantly high degradation rates. Rhodococcus jialingiae djl-6-2 and Rhodococcus sp. djl-6 could degrade 94\% and almost $100 \%$ carbendazim (100 mg L-1) within 60-hour and 48 hours of incubation, respectively (Wang et al., 2010; Xu et al., 2006). Additionally, Rhodococcus erythropolis djl-11 degraded carbendazim (1000 mg L-1) completely within 3 days of incubation (Zhang et al., 2013). However, no Rhodococcus was found in pesticide-treated soil samples in our study, revealing that different environmental conditions and various selection pressure of carbendazim might result in different adaptation of microbial communities in soils.

\section{Conclusion:-}

Three bacterial strains Pseudomonas sp. CT-VT7, Acinetobacter sp. CT-VT9, and Stenotrophomonas sp. CT-VT13 capable of effectively degrading of and performing chemotaxis towards carbendazim were isolated from a long term carbendazim-treated rice field in Can Tho, Vietnam, revealing that these strains are potential candidates for carbendazim biodegradation. However, further studies should be done to unravel the genetic characteristics as well as the catabolic pathway involved in carbendazim degradation in these bacterial strains for in-situ application such as monitoring carbendazim degrading communities in soils and for bioremediation of carbendazim as well as other pesticides belonging to carbamate group. 


\section{References:-}

1. Alvarado-Gutiérrez, M. L., Ruiz-Ordaz, N., Galíndez-Mayer, J., Santoyo-Tepole, F., Curiel-Quesada, E., García-Mena, J., \&Ahuatzi-Chacón, D. (2017). Kinetics of carbendazim degradation in a horizontal tubular biofilm reactor. Bioprocess and Biosystems Engineering, 40(4), 519-528.

2. Arya, R., \& Sharma, A. K. (2015). Bioremediation of carbendazim, a benzimidazole fungicide using Brevibacillus borstelensis and Streptomyces albogriseolus together. Current Pharmaceutical Biotechnology, 17(2), 185-189.

3. Baude, F. J., Pease, H. L., \& Holt, R.F. (1974). Fate of benomyl on field soil and turf. Journal of Agricultural and Food Chemistry, 22(3), 413-418.

4. Berglof, T., Van Dung, T., Kylin, H., \& Nilsson, I. (2002). Carbendazim sorption-desorption in Vietnamese soils. Chemosphere, 48(3), 267-273.

5. Breugelmans, P., \& Uyttebroek, M. (2004). Protocol for DNA extraction and purification. Laboratory of soil and water management, KU Leuven, Belgium.

6. Cancela, G. D., Taboada, E. R., \& Sáchez-Rasero, F. (1992). Carbendazim adsorption on montmorillonite, peat and soils. Journal of Soil Science, 43, 99-111.

7. Fang, H., Wang, Y., Gao, C., Yan, H., Dong, B., \& Yu, Y. (2010). Isolation and characterization of Pseudomonas sp. CBW capable of degrading carbendazim. Biodegradation, 21(6), 939-946.

8. Fleeker, J. R., Lacy, H. M., Schultz, I. R. \& Houkom, E. C. (1974). Persistence and metabolism of thiophanatemethyl in soil. Journal of Agricultural and Food Chemistry, 22, 592-595.

9. Grimm, A., \& Hardwood, C. S. (1997). Chemotaxis of Pseudomonas spp. to the polyaromatic hydrocarbon naphthalene. Applied and Environmental Microbiology, 63(10), 4111-4115.

10. Habe, H., \& Omori, T. (2005). Genetic of polycyclic aromatic hydrocarbon metabolism in diverse aerobic bacteria. Bioscience, Biotechnology, and Biochemistry, 67(2), 225-243.

11. Helweg, A. (1977). Degradation and adsorption of carbendazim and 2-aminobenzimidazole in soil. Pesticide Science, 8, 71-78.

12. Lamers, M., Anyusheva, M., La, N., Nguyen, V.V., \& Strect, T. (2011). Pesticide pollution in surface- and groundwater by paddy rice cultivation: a case study from Nothern Vietnam. Clean - Soil, Air, Water, 39(4), 356-361.

13. Liu, F. Y., Hong, M. Z., Liu, D. M., Li, Y. W., Shou, P. S., Yan, H., \& Shi, G. Q. (2007). Biodegradtion of methyl parathion by Acinetobacter radioresistens USTB-04. Journal of Environmental Science, 19(10), 12571260.

14. Mazellier, P., Leroy, E., Laat, J.T., \& Legube, B. (2003). Degradation of carbendazim by UV/H2O2 investigated by kinetic modeling. Environmental Chemistry Letters, 1, 68-72.

15. Minh, T.B., Iwata, H., Takahashi, S., Viet, P.H., Tuyen, B.C., \& Tanabe, S. (2008). Persistent organic pollutants in Vietnam: environmental contamination and human exposure. Reviews of Environmental Contamination and Toxicology, 193, 213-290.

16. Morinaga, H., Yanase, T., Nomura, M., Okabe, T., Goto, K., Harada, N., \& Nawata, H. (2004). A benzimidazole fungicide, benomyl, and its metabolite, carbendazim, induce aromatase activity in a human ovarian granulose-like tumor cell line (KGN). Endocrinology, 145(4), 1860-1869.

17. Nakai, M., Hess, A. R., Moore, J. B., Gutroff, F. G., Strader. F. L., \& Linder, E. R. (1992). Acute and long-term effects of a single dose of the fungicide carbendazim (methyl 2-benzimidazole carbamate) on the male reproductive system in the rat. Journal of Andrology, 13(6), 507-518.

18. Nakai, M., Miller, M. G., Carnes, K., \& Hess, R. A. (2002). Stage-specific effects of the fungicide carbendazim on Sertoli cell microtubules in rat testis. Tissue Cell, 34(2), 73-80.

19. Nguyen, T. P. O. (2014). Genetic assessment of pesticide-degrading bacteria in the Mekong delta of Vietnam. PhD thesis. KU Leuven, Belgium. ISBN 978-90-8826-370-5.

20. Pailan, S., Sengupta, K., Ganguly, U., \& Saha, P. (2016). Evidence of biodegradation of chlopyrifos by a newly isolated heavy metal-tolerant bacterium Acinetobacter sp. strain MemCl4. Environmental Earth Sciences, 75(12), 1-10.

21. Parales, R. E., Ditty, J. L., \& Hardwood, C. S. (2000). Toluene-degrading bacteria are chemotactic towards the environmental pollutants benzene, toluene, and trichloroethylene. Applied and Environmental Microbiology, 66(9), 4098-4104. 
22. Rajeswary, S., Kumaran, B., Ilangovan, R., Yuvaraj, S., Sridhar, M., Venkataraman. P., Srinivasan, N., \& Aruldhas, M. M. (2007). Modulation of antioxidant defense system by the environmental fungicide carbendazim in Leydig cells of rats. Reproductive Toxicology, 24(3-4), 371-380.

23. Salunkhe, V. P., Sawant, I. S., Banerjee, K., Wadkar, P. N., Sawant, S. D., \& Hingmire, S. A. (2014). Kinetics of degradation of carbendazim by B. subtilis strains: possibility of in situ detoxification. Environmental Monitoring and Assessment, 186(12), 8599-8610.

24. Singh, P., Suri, C. R., \& Cameotra, S. S. (2004). Isolation of a member of Acinetobacter species involved in atrazin degradation. Biochemical and Biophysical Research Communications, 317(3), 697-702.

25. Singhal, L. K., Bagga, S., Kuma, R., \& Chauhan, R. S. (2003). Down regulation of humoral immunity in chickens due to carbendazim. Toxicology in Vitro, 17(5-6), 687-692.

26. Solel, Z., Sandler, D., \& Dinoor, A. (1979). Mobility and persistence of carbendazim and thiabendazole applied to soil via drip irrigation. Phytopathology, 69(12), 1273-1277.

27. Sun, J., Xu, J., Hu, H., \& Hu, M. (2013). Bacterium for efficiently degrading residual pesticide carbendazim and application threof. Chinese Patent No. CN1022906041 B. China Patent and Trademark Office.

28. Thuy, P. T., Van Geluwe, S., Nguyen, V., \&Van der Bruggen, B. (2012). Current pesticide practices and environmental issues in Vietnam: management challenges for sustainable use of pesticides for tropical crops in (South-East) Asia to avoid environmental pollution. Journal of Material Cycles and Waste Management, 14(4), 379-387.

29. Toan, P. V., Sebesvari, Z., Bläsing, M., Rosendahl, I., Renaud, F. G. (2013). Pesticide management and their residues in sediments and surface and drinking water in the Mekong Delta, Vietnam. Science of the Total Environment, 452-453, 28-39.

30. Wang, Z., Wang, Y., Gong, F., Zhang, J., Hong, Q., \&Li, S. (2010). Biodegradation of carbendazim by a novel actinobacterium Rhodococcus jialingiae djl-6-2. Chemosphere, 81(5), 639-644.

31. Wilmotte, A., Van der Auwera, G., \&De Wachter, R. (1993). Structure of the 16 S ribosomal RNA of the thermophilic cyanobacterium Chlorogloeopsis HTF ('Mastigocladus laminosus HTF') strain PCC7518, and phylogenetic analysis. FEBS Letters, 317(1-2), 96-100.

32. Xie, S., Liu, J., Li, L., \& Qiao, C. (2009). Biodegradation of malathion by Acinetobacter johnsonii MA19 and optimization of cometabolism substrates. Journal of Environmental Sciences (China), 21(1), 76-82.

33. Xu,. J. L., Gu, X. Y., Shen, B., Wang, Z. C., Wang, K., \& Li, S. P. (2006). Isolation and characterization of a carbendazim-degrading Rhodococcus sp. djl-6. Current Microbiology, 53(2006), 72-76.

34. Yarden, O., Salomon, R., Katan, J. \& Aharonson, N. (1990). Involvement of fungi and bacteria in enhanced and nonenhanced biodegradation of carbendazim and other benzimidazole compounds in soil. Canadian Journal of Microbiology, 36, 15-23.

35. Yu, G., Liu, Y., Xie L., \& Wang, X. (2009). Involvement of Sertoli cells in spermatogenic failure induced by carbendazim. Environmental Toxicology and Pharmacology, 27(2), 287-292.

36. Zhang, G. S., Jia, X. M., Cheng, T. F., Ma, X. H., \& Zhao, Y. H. (2005). Isolation and characterization of a new carbendazim-degrading Ralstonia sp. strain. World Journal of Microbiology and Biotechnology, 21(3), 265-269.

37. Zhang, X., Huang, Y., Harvey, P. R., Li, H., Ren, Y., Li, J., Wang, J., \& Yang, H. (2013). Isolation and characterization of carbendazim-degrading Rhodococcus erythropolis djl-11. PLoS ONE, 8(10), e74810. 